\title{
Cultural adaptation and psychometric evaluation of the Chinese version of the nurse-specific end-of-life professional caregiver survey: a cross-sectional study
}

Zhijie Zou ${ }^{1,2}$, Jinbing Bai ${ }^{3}$, Yaohua Gu², Qihua Zou², Canhua Xiao ${ }^{3}$, Jiong Yang ${ }^{1 *}$, Qing Zhang ${ }^{2 *}$ (D) and Mark Lazenby ${ }^{4,5}$

\begin{abstract}
Background: Nurses' palliative and hospice care-specific education is associated with the quality of palliative and hospice care that influences health outcomes of patients with life-limiting illnesses and their caregivers. However, China lacks measures available to assess nurses' educational needs in palliative and hospice care. The End-of-Life Professional Caregiver Survey (EPCS) is a psychometrically reliable self-reporting scale to measure multidisciplinary professionals' palliative and hospice care educational needs. This study was performed to explore the psychometric properties of the Chinese version of the EPCS (EPCS-C) among Chinese nurses.

Methods: We translated and culturally adapted the EPCS into Chinese based on Beaton and colleagues' instrument adaptation process. A cross-sectional study design was used. We recruited 312 nurses from 1482 nurses in a tertiary hospital in central China using convenience sampling to complete the study. Participants completed the EPCS-C and a demographic questionnaire. Exploratory and confirmatory factor analysis was carried out to test and verify the construct validity of the nurse-specific EPCS-C. Cronbach's alpha coefficient was used to appraise the reliability of the nurse-specific EPCS-C.

Results: A three-factor structure of EPCS-C was determined, including cultural, ethical, and national values; patientand family-centered communication; and effective care delivery. The exploratory factor analysis explained $70.82 \%$ of the total variances. The 3-factor solution of the nurse-specific EPCS-C had a satisfactory model fit: $x 2=537.96, \times 2 /$ $\mathrm{df}=2.96, \mathrm{CFI}=0.94, \mathrm{RMSEA}=0.079, \mathrm{IFI}=0.94$, and $\mathrm{GFI}=0.86$. Cronbach's alpha coefficient of the overall questionnaire was 0.96

Conclusions: The nurse-specific EPCS-C showed satisfactory reliability and validity to assess nurses' palliative and hospice care educational need. Further research is required to verify the reliability and validity of the EPCS-C in a larger sample, especially the criterion-related validity.
\end{abstract}

Keywords: Palliative and hospice care, Chinese version, Nurse, Educational needs, Reliability, Validity

\footnotetext{
* Correspondence: yangjiongwh@126.com; 00008660@whu.edu.cn

Qing Zhang will handle correspondence at all stages of refereeing and publication.

'Department of Respiratory and Critical Care Medicine, Zhongnan Hospital of Wuhan University, Wuhan, Hubei, China

${ }^{2}$ Wuhan University School of Health Sciences, Wuhan, Hubei, China

Full list of author information is available at the end of the article
}

(c) The Author(s). 2021 Open Access This article is licensed under a Creative Commons Attribution 4.0 International License, which permits use, sharing, adaptation, distribution and reproduction in any medium or format, as long as you give appropriate credit to the original author(s) and the source, provide a link to the Creative Commons licence, and indicate if changes were made. The images or other third party material in this article are included in the article's Creative Commons licence, unless indicated otherwise in a credit line to the material. If material is not included in the article's Creative Commons licence and your intended use is not permitted by statutory regulation or exceeds the permitted use, you will need to obtain permission directly from the copyright holder. To view a copy of this licence, visit http://creativecommons.org/licenses/by/4.0/. The Creative Commons Public Domain Dedication waiver (http://creativecommons.org/publicdomain/zero/1.0/) applies to the data made available in this article, unless otherwise stated in a credit line to the data. 


\section{Background}

Every year, over 56.8 million people in the world are estimated to require palliative care [1]. With a population of more than 1.4 billion [2], China has a huge population in need of palliative care. In 2015, the Quality of Death Index ranked China 71/80 in quality of death and 69/80 in quality of palliative care [3]. Thus, China needs a large workforce with palliative care education and training to provide quality palliative care and improve the quality of death through hospice.

Over the past 25 years, awareness and expansion of palliative and hospice care in China has improved. However, nurses still lack education and training on palliative and hospice care [4-6]. One investigation showed that over $60 \%$ of nurses in hospitals of a major Chinese city had never heard of palliative and hospice care [5]. To decrease the gap in this area, the National Health and Family Planning Commission of the People's Republic of China released detailed guidelines on palliative and hospice care, which include basic standards and management standards for hospice center (trial) [7] and practice guidelines for hospice care (trial) [8]. These guidelines have spawned educational efforts (trainings, workshops, conferences, and courses) for professional palliative and hospice care providers, in particular for nurses, to satisfy their education needs and to enhance their knowledge, attitudes, and self-efficacy of delivering palliative and hospice care. However, there is a paucity of standardized and validated instruments in Chinese to measure nurses' palliative and hospice care educational needs and selfefficacy.

The End-of-Life Professional Caregiver Survey (EPCS see Additional file 1) is a self-reporting scale to measure multidisciplinary professionals' palliative and hospice care educational needs [9-12]. The EPCS was developed in the United States [9] and covers all 8 domains as suggested by American National Clinical Practice Guidelines for Palliative care $[13,14]$ and the modules of the End-of-Life Nursing Education Consortium (ELNEC) curricula $[15,16]$. This EPCS has been widely used in United States $[10,11]$ and has been tested in other cultural contexts $[12,17,18]$. The EPCS has good psychometric properties, with the Cronbach's alpha of whole scale and each dimension reported by Lazenby and colleagues as $0.96,0.95,0.89$, and 0.87 [9]. Until now, China has lacked measures available to assess nurses' specific educational needs in palliative and hospice care.

\section{Methods}

\section{Aim}

The aim of this study was to translate and culturally adapt the EPCS to access the palliative and hospice care educational needs among Chinese nurses. We reported the translation, cultural adaptation, and psychometric evaluation of the Chinese version of the EPCS (EPCS-C).

\section{Design and setting}

The cross-sectional study was implemented on 57 units of a Level A tertiary hospital in central China. The hospital employs 1542 nurses. The data collection was completed between November 2018 and January 2019.

\section{Participants}

Nurses were eligible for the study if they were currently working as a registered nurse in China with at least one year of experience and the ability to complete questionnaires in Modern Standard Chinese (Mandarin). Nurses who were in training as new nurses were excluded.

Nunnally and Bernstein's psychometric theory [19] of 5-10 participants per item was adopted to guide the sample size calculation. With 28 items in the EPCS, the estimated sample size would be between 140 and 280 . Taking into account a projected $85 \%$ completion rate, the total sample size was 329 in this study.

\section{Developing the Chinese version of nurse-specific EPCS}

The EPCS consists of 28 items representing three factors: 12-item Patient- and Family-Centered Communication (PFCC) factor; 8-item Cultural and Ethical Values (CEV) factor; and 8-item Effective Care Delivery (ECD) factor. A 5-point Likert scale ranging from 0 to 4 was used to scale each item. Adding all items' scores produces the total score, ranging 0-112. A higher total score suggests fewer educational needs.

We obtained the English version of the EPCS from the official website and acquired the permission from the original developer (ML) to translate it into a Chinese version. We translated and culturally adapted the EPCS into a Chinese version based on Beaton and colleagues' cross-cultural adaptation process [20]. Two bilingual (Chinese and English) nurse scientists (YG \& ZZ) independently performed the forward translation. A third nurse scientist (XP) synthesized both forward-translated versions into one Chinese version and arbitrated disagreements until the translators reached consensus that the forward-translated EPCS-C was consistent with the original one from the perspective of language and culture. Using the final forward-translated, another bilingual (native Chinese and near-native English) translator (SC) back-translated the Chinese version into English. The original developer of the questionnaire (ML) and a monolingual English-speaking advanced practice palliative and hospice nurse (CE) compared the backtranslated EPCS with the original one and made suggestions. Then, four translators (YG, ZZ, XP, SC) and a monolingual Chinese-speaking palliative and hospice nurse (LF) modified and obtained the pre-final EPCS-C 
by reaching consensus on semantic, habitual, experiential, and conceptual equivalence of all items.

The pre-final EPCS-C was tested on 24 nurses who came from the Level A tertiary hospital and fit inclusion criteria. Nurses read the pre-final version of the EPCS on paper printout. Then a research assistant interviewed them to ask which items were unclear or not understandable and recorded their answers and suggestions for rewording. From these interviews, misunderstood words and phrases were identified. Items were changed as necessary to form the final Chinese version of the nurse-specific EPCS, which was then used for validation. Three items were reworded after investigators conducted interviews to assess clarity and understandability.

\section{Data collection}

Nurses working in an affiliated hospital of Wuhan University were recruited by electronic advertisements which briefly stated the study's aim and procedure. The electronic advertisements together with an online questionnaire link made by Wenjuanxing [21], a professional online questionnaire survey, evaluation, and voting platform, were sent to unit managers. This link allowed nurses to view the informed consent form and choose whether or not to agree to participate in anonymous surveys. Only after the nurse clicked the option of being aware of the informed consent and agreeing to take part in in the survey would the page jump to the questionnaire page. The questionnaire page included a general information questionnaire developed by researchers and the EPCS-C. The survey would end if the agreeing to participate option was not clicked. A total of 329 questionnaires were collected, of which 15 were removed because the participants had not been worked in nursing for more than one year and 2 were removed because of too much missing data. Thus, the final number of samples to be analyzed was 312 .

\section{Data analysis}

All the data were analyzed using SPSS 22.0 and Amos 17.0. Two-tailed significance tests were performed with a $p$ value of 0.05 as the significance level. Participant demographic characteristics were described using mean (standard deviation), frequencies (percentage), and measures of central tendency and dispersion.

We used a 3-step process to validate the nurse-specific EPCS-C.

Step 1: Content Validity. Content validity was assessed in the translation and adaptation of the EPCS-C and was established with $100 \%$ agreement among investigators.

Step 2: Internal Consistency. Cronbach's $\alpha$ coefficient was calculated to appraise the internal consistency of total scale and each subscale. We considered a value of 0.6 or higher for each subscale and a value of 0.7 or higher for the whole scale as adequate internal consistency [22, 23].

Step 3: Construct Validity. Exploratory factor analysis (EFA) and confirmatory factor analysis (CFA) were used. Prior to performing EFA, we conducted KaiserMyer-Olkin (KMO) test and Bartlett's test to ascertain the factorability [24]. The EFA was used to seek the factor structure of nurse-specific EPCS-C and provide information for generating a modified factor solution. The number of factors reserved to rotation was determined through an Eigenvalue $\geq 1$, the scree plot, and the explainability of the different factor solutions generated. The item loading of factors were extracted by the principal component analysis with varimax rotation. Then, the CFA was carried out to certify the construct validity of the proposed modified factor solution through computing standardized factor loadings and model fit indices. A loading value of 0.4 or more for a factor means that the item can be attributed to the underlying factor [25]. Model fit indices, involving model $\chi^{2}$, $\chi^{2} / \mathrm{df}$, comparative fit index (CFI), incremental fit index (IFI), root-meansquare error of approximation (RMSEA), and goodnessof-fit index (GFI), were applied to evaluate the goodness of fit of the model. If $\mathrm{x} 2 / \mathrm{df} \leq 3, \mathrm{CFI}>0.90$, RMSEA $<$ 0.06 , IFI $>0.90$, and GFI $>0.90$, the model fitting was admissible [25]. $\mathrm{Hu}$ and Bentler suggested that the model had a fair fit if RMSEA was between 0.05 and 0.08 [26].

We analyzed the influence of age, length of work in year, school education on palliative and hospice care, and the related training at work on participants' scores on the nurse-specific EPCS-C using Spearman Correlation and liner regression analyses.

\section{Results \\ Participants}

The participants' general information are shown in Table 1. The majority of participants were female (92.9\%) and had a bachelor's degree in nursing (89.7\%). The mean age of participants was $28.96 \pm 5.78$ years. On average, they worked as a nurse for $7.2 \pm 6.4$ years. Most participants (82.4\%) had experience of caring for a dying patient, while fewer (22.1\%) had cared for a dying patient within the last month.

\section{Construct validity}

The KMO value of the nurse-specific EPCS-C was 0.964 and Bartlett's test was highly significant $(p<0.001)$. Thus, EFA was conducted. After conducting the principal component analysis with Varimax rotation [25], three factors emerged with a cumulative variance of 70.71\%, including 14-item Factor 1 (eigenvalue 16.6; variance 59.1\%); 6-item Factor 2 (eigenvalue 2.1; variance 7.4\%); and 8-item Factor 3 (eigenvalue 1.2; variance 
Table 1 Characteristics of participants $(N=312)$

\begin{tabular}{|c|c|c|c|}
\hline & Mean (SD) & Range & n (\%) \\
\hline Age, year & $28.96(5.78)$ & $21-50$ & \\
\hline \multicolumn{4}{|l|}{ Sex } \\
\hline female & & & $290(92.9$ \\
\hline male & & & $22(7.1)$ \\
\hline \multicolumn{4}{|l|}{ Marital status } \\
\hline married & & & $174(55.8$ \\
\hline divorced & & & $1(0.3)$ \\
\hline single & & & $137(43.9)$ \\
\hline \multicolumn{4}{|l|}{ Highest academic degree } \\
\hline technical secondary school & & & $1(0.3)$ \\
\hline junior college/Diploma & & & $24(7.7)$ \\
\hline Bachelor of Science in Nursing & & & $280(89.7)$ \\
\hline Master of Science in Nursing & & & $7(2.2)$ \\
\hline \multicolumn{4}{|l|}{ Religious belief } \\
\hline no & & & $295(94.6$ \\
\hline buddhism & & & $14(4.5)$ \\
\hline christianity & & & $1(0.3)$ \\
\hline others & & & $2(0.6)$ \\
\hline Working as a nurse, year & $7.25(6.42)$ & $1-31.42$ & \\
\hline \multicolumn{4}{|l|}{ Title } \\
\hline nurse & & & $83(26.6)$ \\
\hline senior nurse & & & $178(57.1)$ \\
\hline supervisor nurse & & & $50(16)$ \\
\hline associate professor of nursing & & & $1(0.3)$ \\
\hline \multicolumn{4}{|l|}{ Position } \\
\hline staff nurse & & & $304(97.4$ \\
\hline head nurse & & & $7(2.2)$ \\
\hline nursing division manager & & & $1(0.3)$ \\
\hline School education on palliative care & $0.95(0.85)$ & 0 (none) - 3 (sufficient) & \\
\hline Training at work on palliative care & $1.16(0.90)$ & 0 (none) - 3 (sufficient) & \\
\hline \multicolumn{4}{|l|}{ Cared for a dying patient } \\
\hline yes & & & $257(82.4)$ \\
\hline no & & & $55(17.6)$ \\
\hline \multicolumn{4}{|c|}{ The latest time of caring a dying patient } \\
\hline within 1 week & & & $33(10.6)$ \\
\hline within 1 month & & & $66(21.2)$ \\
\hline within 3 months & & & $59(18.9)$ \\
\hline within 6 months & & & $28(9.0)$ \\
\hline within 12 months & & & $71(22.8)$ \\
\hline
\end{tabular}

4.1\%). All item loadings were $>0.50$. Four items $(6,7,8$, 14) were removed due to high cross-loadings in two factors (both >0.50).

The KMO value of the 24 items was 0.96 and Bartlett's test was highly significant $(p<0.001)$. The new three- factor model emerged with a cumulative variance of 71.60\%, including 14-item Factor 1 (eigenvalue 14.41; variance 60.06\%); 5-item Factor 2 (eigenvalue 1.72; variance 7.18\%); and 5-item Factor 3 (eigenvalue 1.05; variance $4.36 \%)$. We removed another three original items 
$(19,23,24)$ according to modification indices produced by the AMOS program and the researchers' judgement.

The final EFA was conducted for the 21-item EPCS-C. The KMO value was 0.96 and the Bartlett's test was highly significant $(p<0.001)$. The final three factors emerged (Table 2) with a cumulative variance of $70.82 \%$ : 11-item Factor 1 (eigenvalue 12.37; variance 58.90\%); 5item Factor 2 (eigenvalue 1.46; variance 6.95\%); and 5item Factor 3 (eigenvalue 1.04; variance 4.97\%). According to the item content, we named Factor 1 the Cultural, Ethical, and National Values (CENV), Factor 2 the PFCC, Factor 3 the ECD subscales.

The CFA was performed for the final proposed factor solution. According to modification indices, correlations between error variances were allowed to advance model fit [27]. The model fit indices were: $\mathrm{X}^{2}=537.96, \mathrm{X}^{2} / \mathrm{df}=$ 2.96, $\mathrm{CFI}=0.94, \mathrm{RMSEA}=0.079, \mathrm{IFI}=0.94$, and $\mathrm{GFI}=$ 0.86 . The standardized factor loadings for the final model ranged from 0.60 to 0.89 and were all statistically significant (Fig. 1). Thus, a final new 3-factor model was validated, namely the nurse-specific EPCS-C (see Additional file 2) model. Table 3 compares the factor structures between the original model [9] and the nursespecific EPCS-C model.

\section{Internal consistency}

Cronbach's alpha coefficients of the 21-item nurse specific EPCS-C and its PFCC, CENV and ECD subscales were $0.96,0.89,0.96$ and 0.86 , respectively (Table 4 ).

\section{Nurses-specific EPCS-C score}

The mean total score of the nurse-specific EPCS-C was $44.88 \pm 16.49$. Nurses scored higher score on the Effective Care Delivery subscale (mean per item $=2.45 \pm 0.78$ ) but lower on the Cultural, Ethical, and National Values subscale (mean per item $=1.97 \pm 0.88$ ). For individual items, the lowest scoring item was "I am familiar with palliative care principles and national guidelines" (1.70 \pm 1.08). (Details are presented in Tables 2 and 4).

School education on palliative and hospice care and the related training at work were associated with the nurse-specific EPCS-C score (Table 5). Marital status, clinical title, whether cared for a dying patient, and the latest time of caring a dying patient were not associated

Table 2 Loading value from the last EFA for EPCS-C and mean of each item

\begin{tabular}{|c|c|c|c|c|c|}
\hline \multirow[t]{2}{*}{ Factor } & \multirow{2}{*}{$\begin{array}{l}\text { Original } \\
\text { EPCS } \\
\text { Item } \\
\text { Number }\end{array}$} & \multicolumn{3}{|c|}{ Factor Loadings } & \multirow[t]{2}{*}{ Mean (SD) } \\
\hline & & Factor 1 & Factor 2 & Factor 3 & \\
\hline \multirow[t]{11}{*}{ Cultural, Ethical, and National Values } & 22 & .844 & .215 & .149 & $1.70(1.079)$ \\
\hline & 21 & .800 & .220 & .322 & $1.91(1.047)$ \\
\hline & 25 & .798 & .254 & .157 & $1.92(1.076)$ \\
\hline & 27 & .790 & .383 & .140 & $1.79(1.080)$ \\
\hline & 26 & .761 & .345 & .167 & $1.85(1.059)$ \\
\hline & 20 & .754 & .219 & .387 & $1.99(1.016)$ \\
\hline & 18 & .738 & .353 & .343 & $2.04(0.989)$ \\
\hline & 16 & .728 & .349 & .314 & $1.98(1.035)$ \\
\hline & 13 & .636 & .388 & .397 & $2.09(0.956)$ \\
\hline & 28 & .600 & .333 & .368 & $2.20(1.073)$ \\
\hline & 17 & .577 & .237 & .467 & $2.16(1.048)$ \\
\hline \multirow[t]{5}{*}{ Patient- and Family-Centered Communication } & 4 & .196 & .756 & .166 & $2.19(1.149)$ \\
\hline & 2 & .272 & .735 & .366 & $2.35(1.015)$ \\
\hline & 3 & .346 & .731 & .325 & $2.15(1.052)$ \\
\hline & 1 & .318 & .711 & .220 & $2.19(1.005)$ \\
\hline & 5 & .439 & .671 & .206 & $2.14(1.062)$ \\
\hline \multirow[t]{5}{*}{ Effective Care Delivery } & 9 & .052 & .206 & .818 & $2.94(0.903)$ \\
\hline & 11 & .354 & .276 & .697 & $2.31(0.976)$ \\
\hline & 10 & .420 & .215 & .682 & $2.29(0.943)$ \\
\hline & 12 & .390 & .472 & .582 & $2.34(0.985)$ \\
\hline & 15 & .392 & .353 & .510 & $2.35(1.026)$ \\
\hline
\end{tabular}




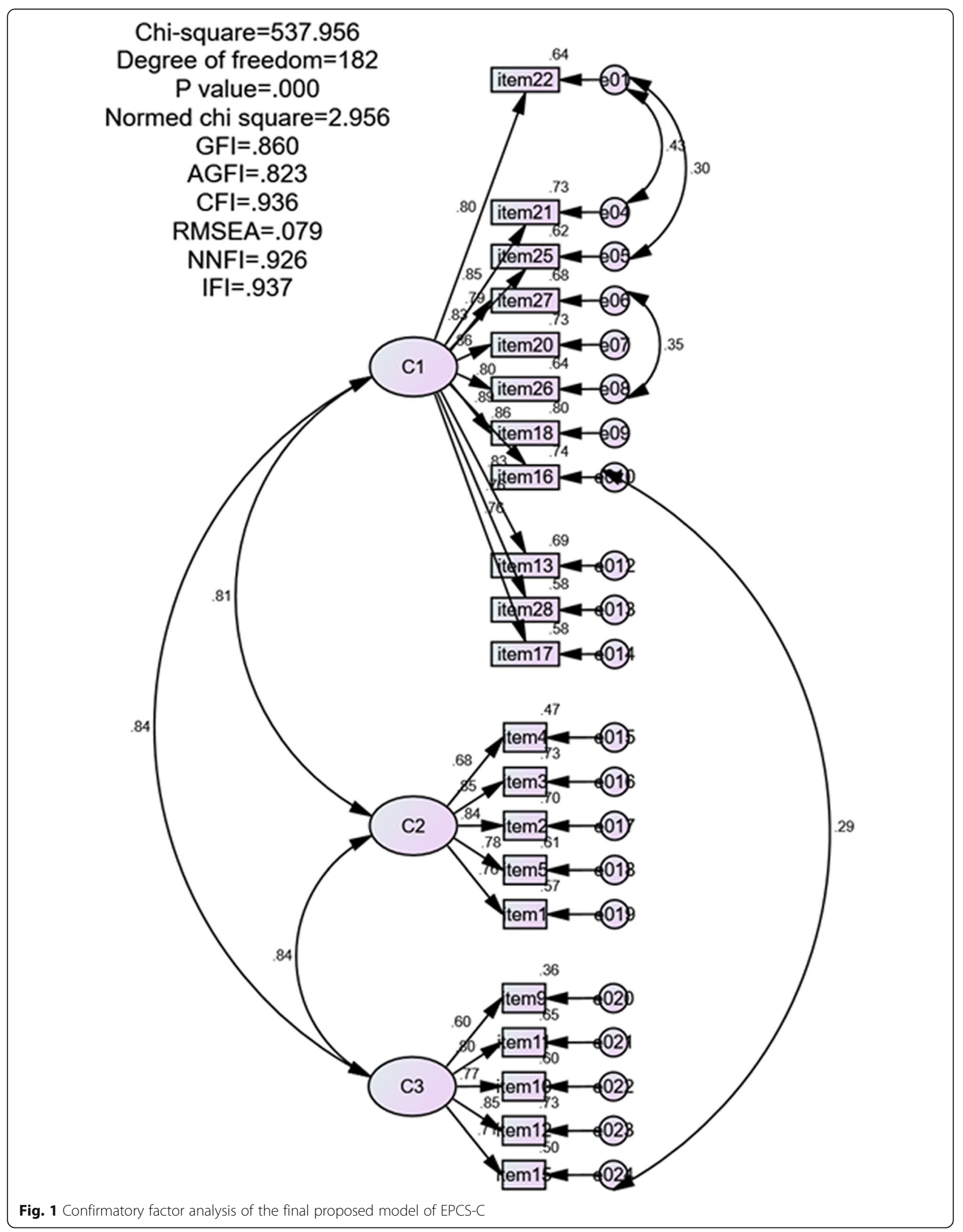


Table 3 Comparison of the factor structures between the original model and the proposed model

\begin{tabular}{llll}
\hline Proposed model (21 items) & & & \multicolumn{2}{l}{ Original model (28 items) } \\
\cline { 1 - 2 } Subscale & items & Subscale & items \\
\hline PFCC & $1,2,3,4,5$ & PFCC & $1,2,3,4,5,6,7,8,9,10,11,12$ \\
CENV & $13,16,17,18,20,21,22,25,26,27,28$ & CEV & $13,14,15,16,17,18,19,20$ \\
ECD & $9,10,11,12,15$ & ECD & $21,22,23,24,25,26,27,28$ \\
\hline
\end{tabular}

Note: PFCC patient- and family-centered communication, CENV cultural, ethical, and national values, CEV Cultural and Ethical Values, ECD effective care delivery

with the EPCS-C score. The regression results showed that training on palliative and hospice care at work was the only one factor that predicted EPCS mean scores (Table 6).

\section{Discussion}

The purpose of this study was to translate and culturally adapt the EPCS for use among Chinese nurses. The EPCS is widely used to measure multidisciplinary professionals' palliative and hospice care educational needs. We followed Beaton et al.'s cross-cultural adaptation process to translate the EPCS into Chinese and tested its psychometric properties among Chinese nurses [20]. Data from a total of 312 nurses were analyzed and results showed that the 21-item nurse-specific EPCS-C exhibits strong internal reliability and construct validity.

Both EFA and CFA were carried out to test and verify the construct validity of the nurse-specific EPCS-C. All the analyses suggested three factors -CENV, PFCC, and ECD, which was consistent with the original EPCS. Based on the CFA, the final nurse-specific EPCS-C showed a satisfactory model fit. Furthermore, the high standardized factor loadings of each subscale verified the construct validity of the nurse-specific EPCS-C. The nurse-specific EPCS-C had high Cronbach's alpha coefficients on both the whole scale and the three subscales, ranging from $0.86-0.96$. Therefore, the EPCS-C is a reliable instrument for assessing palliative and hospice care education needs among nurses [28].

Until now, only the scales testing people's knowledge of and attitudes toward palliative and hospice care had been translated into Chinese, such as the Palliative Care

Table 4 The Cronbach's alpha coefficients and score of the EPCS-C

\begin{tabular}{llll}
\hline Factor & $\begin{array}{l}\text { Cronbach's alpha } \\
\text { coefficient }\end{array}$ & $\begin{array}{l}\text { Mean } \\
\text { score } \\
\text { Mean (SD) }\end{array}$ & $\begin{array}{l}\text { Mean score per } \\
\text { item } \\
\text { Mean (SD) }\end{array}$ \\
\hline PFCC & 0.887 & $11.02(4.39)$ & $2.20(0.88)$ \\
CENV & 0.956 & $21.63(9.66)$ & $1.97(0.88)$ \\
ECD & 0.864 & $12.23(3.90)$ & $2.45(0.78)$ \\
Total & 0.964 & 44.88 & $2.14(0.79)$ \\
& & $(16.49)$ & \\
\hline
\end{tabular}

Note: PFCC patient- and family-centered communication, CENV cultural, ethical, and national values, $E C D$ effective care delivery
Quiz for Nursing [6, 29] and Frommelt Attitudes Toward Care Of the Dying Scale [30, 31]. Besides knowing nurses' exact knowledge of and their attitudes toward palliative and hospice care, the increasing national emphasis on palliative and hospice care in China makes it imperative that we know nurses' educational needs, to provide tailored training. The nurse-specific EPCS-C is a valid instrument for assessing nurses' education needs.

However, we did note differences between the EPCS-C and the EPCS, which are common when the factor structure of a scale is tested under different cultural contexts [20, 32]. First, compared to the original 28-item EPCS, the EPCS-C includes 21 items. Some original items were deleted because they were almost equally loaded on 2 factors, making them indistinguishable. Some items were removed according to modification indices achieving by the AMOS program and the researchers' judgement. Moreover, some items were moved to another factor instead of the original one. In fact, there are not only differences but also connections among the three factors. For example, original item 11 ("I know how to use non-drug therapies in management of patients' symptoms") (see Additional file 1) was moved from the PFCC subscale to the ECD subscale. Non-drug therapies include different therapies besides communication, such as musical therapy, mindfulness-based cognitive therapy, meditation and so forth, and providing them is considered effective care delivery. But, the final nurse-specific EPCS-C like the original EPCS covers all domains of the American National Clinical Practice Guidelines for Palliative care [14] and the modules of ELNEC curricula [15].

The study showed that training on palliative care at work was an influential factor in EPCS-C score, which was similar with the literature [10]. As we know, the low quality of palliative and hospice care in China [3],

Table 5 Spearman correlation coefficients between EPCS-c and Characteristics of participants

\begin{tabular}{lll}
\hline & \multicolumn{2}{l}{ EPCS-C score } \\
\cline { 2 - 3 } & $\mathbf{r}$ & $\mathbf{p}$ \\
\hline Age & -0.050 & 0.381 \\
Working year & -0.055 & 0.329 \\
School education on palliative care & 0.164 & $\mathbf{0 . 0 0 4}$ \\
Training on palliative care at work & 0.199 & $\mathbf{0 . 0 0 0}$ \\
\hline
\end{tabular}


Table 6 Liner regression on EPCS-C

\begin{tabular}{llllll}
\hline & $\mathbf{B}$ & $\boldsymbol{B}$ & $\mathbf{t}$ & $\mathbf{p}$ & $\mathbf{9 5 . 0 \%}$ Confidence Interval for B \\
\hline (Constant) & 39.640 & & 25.244 & $\mathbf{. 0 0 0}$ & $36.550 \sim 42.730$ \\
School education on palliative care & 1.255 & .065 & 1.003 & .317 & $-1.207 \sim 3.718$ \\
Training at work on palliative care & 3.480 & .190 & 2.940 & $\mathbf{. 0 0 4}$ & $1.151 \sim 5.810$ \\
\hline
\end{tabular}

specific palliative and hospice care education should be advocated for the professional caregivers.

The convenience sampling limited the study. Further study is required to verify the psychometric properties of the EPCS-C in a larger sample, especially the criterionrelated validity. Other scales testing people's knowledge of and attitudes toward palliative and hospice care should be used to test their relevance to the EPCS-C. In addition, some misunderstood words and phrases for nurses were found during pilot test, such as advanced care planning, hospice, palliative care, and spiritual issues. In order to collect data more truthfully, we briefly introduced the above words in the questionnaire of this study and suggested that they should be explained in future studies. Furthermore, we only tested the EPCS-C among nurses. Future work needs to be done on other professionals, especially physicians, who are also important team members of palliative and hospice care. Given the scale of end-of-life care needs in Chinese-speaking populations and the gap in trained nurses to meet those needs, that we now have a validated survey to test Chinese-speaking nurses' educational requirements in palliative and hospice care is a strength of this study.

\section{Conclusions}

The EPCS-C demonstrates sufficient reliability and validity for assessing palliative and hospice care-specific education need among nurses. This scale provides nurse leaders and managers and nursing faculty with an easily administered tool for Chinese-speaking nurses to assess palliative and hospice care-specific educational needs. It also provides researchers with an instrument to explore the effect of education on nurses' provision of palliative and hospice care.

\section{Supplementary Information}

The online version contains supplementary material available at https://doi. org/10.1186/s12904-021-00725-2.

Additional file 1. End-of-Life Professional Caregiver Survey.

Additional file 2. Chinese version of End-of-Life Professional Caregiver Survey.

\section{Abbreviations}

CENV: cultural, ethical, and national values; CEV: Cultural and Ethical Values; CFA: confirmatory factor analysis; CFI: comparative fit index; ECD: effective care delivery; EFA: exploratory factor analysis; ELNEC: End-of-Life Nursing Education Consortium; EPCS: End-of-Life Professional Caregiver Survey; EPCSC: Chinese version of the EPCS; GFI: goodness-of-fit index; IFI: incremental fit index; KMO: Kaiser-Myer-Olkin; PFCC: patient- and family-centered communication; RMSEA: root-mean-square error of approximation

\section{Acknowledgements}

We want to thank the nurses who engaged in this study, and thank Dr. Sandy Chen Stokes, Dr. Carma Erickson-Hurt, Dr. Xianbo Pei and Ms. Feng for supporting the development of the Chinese version of EPCS.

\section{Authors' contributions}

Conceptualization: ZZ; Methodology: ZZ, JB, XC, JY, QZ2, ML; Tool translation: ZZ, YG, ML; Data collection: ZZ, YG, QZ1; Formal analysis: ZZ, YG, ML; Writing - review and editing: ZZ, JB, YG, QZ1, CX, JY, QZ2, ML. Each author has approved the manuscript.

\section{Funding}

This study was financed by the National Innovation and Entrepreneurship training Program for College Students of China [No. 201810486105]. This funding source had no role in the design of this study, the analyses and interpretation of the results, and the preparation and submission of the manuscript.

\section{Availability of data and materials}

The data used during this study are available from the corresponding authors on reasonable request.

\section{Ethics approval and consent to participate}

This study was approved by the Institutional Review Board of Wuhan University School of Medicine (No.2020YF2001). All nurses participated voluntarily. Electronic written informed consents were obtained anonymously from all participants before they completed the questionnaires. The developers of EPCS were contacted for permission to translate and culturally adapt EPCS to Chinese.

\section{Consent for publication}

Not applicable.

\section{Competing interests}

None.

\section{Author details}

${ }^{1}$ Department of Respiratory and Critical Care Medicine, Zhongnan Hospital of Wuhan University, Wuhan, Hubei, China. ${ }^{2}$ Wuhan University School of Health Sciences, Wuhan, Hubei, China. ${ }^{3}$ Emory University Nell Hodgson Woodruff School of Nursing, Atlanta, GA, USA. ${ }^{4}$ Yale University School of Nursing, 400 west Campus Drive, Orange, CT, USA. ${ }^{5}$ University of Connecticut School of Nursing, Storrs, CT, USA.

Received: 30 October 2020 Accepted: 5 February 2021

Published online: 16 February 2021

\section{References}

1. Worldwide Palliative Care Alliance. Global Atlas of Palliative Care, 2nd Ed. [http://www.thewhpca.org/resources/global-atlas-on-end-of-life-care]. Accessed 22 Oct 2020

2. National Bureau of Statistics of the People's Republic of China. Statistical Communique of the People's Republic of China on the 2019 National Economic and Social Development [http://www.stats.gov.cn/tjsj/zxfb/202 002/t20200228_1728913.html]. Accessed 22 Oct 2020.

3. Economist Intelligence Unit. The 2015 Quality of Death Index: Ranking palliative care across the world [https://perspectives.eiu.com/healthcare/201 5-quality-death-index]. Accessed 22 Oct 2020. 
4. Song Y, Wu L, Yuan L, Guo M, Wu B, Wang D. Cognition and attitude on palliative care of nurses in Nanjing area. Chinese Nursing Res. 2018;32(13): 2103-6. https://doi.org/10.12102/j.issn.1009-6493.2018.13.028 In Chinsese.

5. Wang T. Investigation on the palliative care knowledge of medical care personnel in Nanjing top three hospitals. Int J Nurs. 2017;36(09):1193-8. https://doi.org/10.3760/cma.j.issn.1673-4351.2017.09.013 In Chinsese.

6. Zou M. Investigation and analysis on status quo of grasping knowledge about palliative nursing of nurses in Shanghai. Chin J Pract Nurs. 2015: 31(18):1386-90. https://doi.org/10.3760/cma.j.issn.1672-7088.2015.18.019 In Chinsese.

7. National Health and Family Planning Commission of the People's Republic of China. Notice on National Health and Family Planning Commission issuing Basic Standards and Management Standards for Hospice Center (trial). [http://www.nhc.gov.cn/yzygj/s3593/201702/2f50fdc62fa84cdd9d9a 09d5162a661f.shtml]. Accessed 22 Oct 2020.

8. General Office of National Health and Family Planning Commission of the People's Republic of China. Notice on General Office of National Health and Family Planning Commission issuing Practice Guidelines for Hospice Care (Trial). [http://www.nhc.gov.cn/yzygj/s3593/201702/83797c0261a94781b1 58dbd76666b717.shtml]. Accessed 22 Oct 2020.

9. Lazenby M, Ercolano E, Schulman-Green D, McCorkle R. Validity of the endof-life professional caregiver survey to assess for multidisciplinary educational needs. J Palliat Med. 2012;15(4):427-31.

10. O'Shea ER, Lavallee M, Doyle EA, Assessing Palliative MK. End-of-life educational needs of pediatric health care professionals. J Hospice Palliative Nurs. 2017;19(5):468-73.

11. Wallace CL, Cruz-Oliver DM, Ohs JE, Hinyard L. Connecting personal experiences of loss and professional practices in advance care planning and end-of-life care: a survey of providers. Am J Hosp Palliat Care. 2018;35(11): 1369-76.

12. Garcia ACM, Damasceno Spineli VMC, Eduardo AHA, Meireles E, Moreira de Barros GA, Lazenby M. Translation, cultural adaptation, and validation of the Brazilian Portuguese version of the End-of-Life Professional Caregiver Survey. Palliat Support Care. 2020;18(5):569-74. https://doi.org/10.1017/S147895151 9000993. PMID: 31771678.

13. Ferrell B, Connor SR, Cordes A, Dahlin CM, Fine PG, Hutton N, Leenay M, Lentz J, Person JL, Meier DE, et al. The national agenda for quality palliative care: the National Consensus Project and the National Quality Forum. J Pain Symptom Manag. 2007;33(6):737-44.

14. National Consensus Project for Quality Palliative Care. Clinical Practice Guidelines for Quality Palliative Care, 4th edition [https://www.nationalcoa litionhpc.org/ncp/ ]. Accessed 22 Oct 2020.

15. American Association of College of Nursing. End-of-Life Nursing Education Consortium (ELNEC) FACT SHEET. [https://www.aacnnursing.org/Portals/42/ ELNEC/PDF/ELNEC-Fact-Sheet.pdf]. Accessed 22 Oct 2020

16. Ferrell B, Malloy $P$, Mazanec $P$, Virani R. CARES: AACN's new competencies and recommendations for educating undergraduate nursing students to improve Palliative care. J Prof Nurs. 2016;32(5):327-33.

17. Kaasalainen S, Sussman T, Bui M, Akhtar-Danesh N, Laporte RD, McCleary L, Wickson Griffiths A, Brazil K, Parker D. Dal Bello-Haas V et al. what are the differences among occupational groups related to their palliative carespecific educational needs and intensity of interprofessional collaboration in long-term care homes? BMC Palliat Care. 2017;16(1):33.

18. Van den Block $L$, Smets $T$, van Dop N, Adang $E$, Andreasen $P$, Collingridge Moore D, Engels Y, Finne-Soveri H, Froggatt K, Gambassi G et al: Comparing Palliative Care in Care Homes Across Europe (PACE): Protocol of a crosssectional study of deceased residents in 6 EU countries. J Am Med Dir Assoc 2016, 17(6):566 e561-567.

19. Nunnally JC, Bernstein IH (eds.). Psychometric theory, 3rd edition: Tata McGraw-hill education; 1994.

20. Beaton DE, Bombardier C, Guillemin F, Ferraz MB. Guidelines for the process of cross-cultural adaptation of self-report measures. Spine. 2000;25(24):318691.

21. Wenjuanxing.[https://www.wjx.cn/]. Accessed 22 Oct 2020.

22. DeVellis RF. Scale development: theory and applications. Los Angeles, CA: SAGE Publication, Inc.; 2016.

23. Wu ML. Practice on statistical analysis of questionnaire. Chongqing: Chongqing University Press; 2010. In Chinsese

24. Shi W. SPSS19 statistical analysis: from introduction to mastery. Beijing: Tsinghua University Press; 2012. In Chinsese
25. Hair JF, Black WC, Babin B, Anderson RE, Tatham RL. Multivariate Data Analysis. 7th ed. New York: Prentice Hall; 2009.

26. Hu LT, Bentler PM. Cutoff criteria for fit indexes in covariance structure analysis: conventional criteria versus new alternatives. Structural Equation Modeling: Multidisciplinary J. 1999;6(1):1-55.

27. Byrne BM. Structural equation modeling with Amos: basic concepts, application, and programming. New York: Routledge; 2010.

28. Streiner DL, Norman GR, Cairney J. Health measurement scales: a practical guide to their development and use. USA: Oxford University Press; 2015.

29. Ross MM, McDonald B, McGuinness J. The palliative care quiz for nursing (PCQN): the development of an instrument to measure nurses' knowledge of palliative care. J Advanc Nurs. 1996;23(1):126-37.

30. Frommelt KHM. The effects of death education on nurses' attitudes toward caring for terminally ill persons and their families. Am J Hospice Palliative Med. 1991:8(5):37-43.

31. Wang LP, Li YJ, Yan WZ, Li GM. Development and psychometric testing Chinese version of the Frommelt attitude toward Care of the Dying Scale, form B in nurses and nursing students. J Cancer Educ. 2016;31(1):123-30.

32. Gu YH, Xiong L, Bai JB, Hu J, Tan XD. Chinese version of the clinical learning environment comparison survey: assessment of reliability and validity. Nurse Educ Today. 2018;71:121-8.

\section{Publisher's Note}

Springer Nature remains neutral with regard to jurisdictional claims in published maps and institutional affiliations.
Ready to submit your research? Choose BMC and benefit from:

- fast, convenient online submission

- thorough peer review by experienced researchers in your field

- rapid publication on acceptance

- support for research data, including large and complex data types

- gold Open Access which fosters wider collaboration and increased citations

- maximum visibility for your research: over $100 \mathrm{M}$ website views per year

At $\mathrm{BMC}$, research is always in progress.

Learn more biomedcentral.com/submissions 